\title{
Therapeutic mental health effects perceived by outdoor tourists: A large-scale, multi-decade, qualitative analysis
}

\author{
R.C. Buckley \\ Introduction
}

The mental healthcare sector wants to prescribe outdoor therapies, but as yet lacks outdoor capabilities. The tourism sector has those capabilities, but as yet has not shown therapeutic outcomes. Here, therefore, I reanalyse previously published qualitative datasets, to examine mental health effects perceived by outdoor tourists. Outcomes indicate that nature, eco and adventure tourism enterprises could potentially become certified providers of prescribable outdoor therapies in mainstream healthcare. This represents a large economic opportunity, significantly greater than current investment in outdoor education and recreation. From a healthcare perspective, the analysis presented here provides proof of concept only: clinical testing and medical certification are still required. From a tourism perspective, it indicates an opportunity to apply existing skills, under a different commercial model. From a tourism research perspective, it demonstrates a need for more rigorous research on mental health outcomes, beyond emotional experiences.

\section{Context}

In the Western health sector, 35 years' research (Ulrich, 1984; Twohig-Bennett and Jones, 2018) has demonstrated therapeutic benefits of exposure to nature, especially for mental health. This reflects longstanding practices such as forest bathing in some Eastern nations (Chen, Yu, \& Lee, 2018; Oh et al., 2017). As yet, Western research is at proof-of-concept level, lacking quantitative dose- durationresponse data for patients with different characteristics and symptoms (Buckley, Brough, \& Westaway, 2018; Frumkin et al., 2017; Shanahan et al., 2016). Also 
lacking are practical implementation plans within mainstream healthcare systems (Buckley et al., 2018). Policy pressures to create such plans have arisen only recently.

These pressures derive from budget shortfalls in developed nations, owing to ageing populations and increases in chronic disease syndrome, CDS: depression, dementia, diabetes and obesity. Treatment costs for CDS, from health insurance and government healthcare budgets, have increased greatly (Buckley et al., 2018). Poor mental health imposes additional costs, $\sim 10 \%$ of GDP, through reduced workplace productivity and increased antisocial behaviours, both private and public (Buckley et al., 2018). This drives demand for new approaches to CDS. Outdoor therapies, modelled on physiotherapy and psychotherapy courses, are the most promising opportunity (Buckley et al., 2018). To be prescribed by general practitioners, and funded by government or insurers rather than patients, courses must be tested clinically, and delivered by certified providers. These providers must be capable of safe and insurable operations outdoors. This includes equipment, land access, logistics, risks and safety, staff skills and training, and client choreography. The mainstream healthcare industry has little experience in these.

Outdoor nature, eco and adventure tourism enterprises do have the practical skills to provide safe outdoor experiences. But do they provide therapeutic benefits? Outdoor education and recreation can enhance wellbeing (Breitenstein \& Ewert, 1990; Donaldson \& Donaldson, 1958; Konu, 2015; Ohe, Ikei, Song, \& Miyazaki, 2017; Priest, 1986; Smith \& Diekmann, 2017; Smith \& Puczkó, 2016); but this is ignored in mainstream health (Van den Berg, 2017), since clinical psychologists expect double-blind, pre/post-tested, randomised-controlled experimental trials.

Methods

As a first step, here I use qualitative social science methods to identify outdoor 
tourists' own perceptions of mental health outcomes, through reanalysis of previously published datasets. These were obtained ethnographically, using interviews and inter- actions, over periods up to 3 decades for $>100$ informants, and single interviews for $>500$ informants (Buckley, 2016; Buckley \& Ollenburg, 2013). Records included video and written exchanges via email and social-media messaging, as well as notes and memories. Tours included contemplative naturebased activities such as hiking, diving, birdwatching, whale-watching, and wildlife watching; and adventure activities such as multi-day river rafting, sea kayaking, surfing, off-road driving, and expedition cruises. A wide range of prices, durations, environments, and group sizes is included.

Components of these data related to participant perceptions of mental health were reanalysed using grounded-theory coding, classification, and constant-comparison procedures (Glaser \& Strauss, 2017; Stern \& Porr, 2017), widely adopted in tourism research (Matteucci \& Gnoth, 2017). Iterations were repeated until standard completion conditions were satisfied, namely: (i), theoretical saturation, no further concepts identifiable; and (ii), efficient coding, fewest feasible tiers and elements (Aldiabat \& Navenec, 2018; Nelson, 2017; Saunders et al., 2018).

\section{Results}

The coding tree is presented in Table 1. A total of 33 distinguishable concepts were recognised, grouped into 11 lower-tier and 6 higher-tier constructs. The first three of the higher-tier constructs were unsurprising: a range of positive emotions experienced; various words and phrases allied to the term recreation; and comments on friendships and relationships.

The other three were unexpected. They were all related in various ways to mental clarity. The first group emphasised the importance of unambiguous material objects and individual actions, in contrast to the ambiguity of words, language, and untestable information. The second group indicated that once separated from daily 
tasks, obligations, and routines, one's mind gains greater perception and clarity of thought, and this leads to insights and decisions. The third group was even more fundamental: after a period spent outdoors, at least some people focus more on the finite length, purpose, and meaning of their lives.

At least some outdoor tourism experiences can thus provide: positive individual emotions and social interactions; clarity, insight and decisiveness at work and at home; and an improved sense of the purpose and meaning of life. These are all goals of mental health therapies.

Conclusions

Outdoor tourism clients report positive gains in mental health. These include not only immediate emotional effects, identified in previous studies (Roberts, Jones, \& Brooks, 2018); but also longer-term gains in clarity and purpose, not previously identified. Such gains can improve workplace productivity and reduce depression, with substantial economic significance. Outdoor tourism may be seen not as a discretionary personal indulgence, but as a high-return investment in individual mental health. Mental health gains may not be universal: some outdoor tourism may also generate negative emotional experiences for some individuals, though not reported here. The same applies to mental health consequences of nature exposure more generally.

From a health policy perspective, outdoor tourism enterprises could act as readymade providers of outdoor therapies. This would need redesign of tour products as certified courses of therapy. Course designs and certification frameworks are not yet formalised (Buckley et al., 2018). Trials are under way (Niedermeier, Hartl, \& Kopp, 2017; Richardson \& McEwan, 2018; Stelzer, Book, Graessel, Kornhuber, \& Luttenberger, 2018). That research examines outdoor tourism and recreation activities, but has been published in journals of science, psychology and health, not 
tourism.

From a tourism perspective, outdoor therapies could provide a new market, funded by health agencies and insurers in addition to individual clients. To capitalise on this, outdoor tourism providers would need to redesign products, and demonstrate mental health gains for clients. A rigorous test would allocate patients randomly between tour (experimental) and no-tour (control) treatments; and measure mental health pre and post treatment/control, using scales accepted in psychological practice. Replication is required across genders, age brackets, socioeconomic and demographic subsectors, ethnicities and cultural backgrounds (Wang et al., 2017), and outdoor activities and environments (White et al., 2016; Wyles et al., 2017); with controls for effects via physical and social health. This is a large research task, but the results reported here suggest that it would be a worthwhile investment.

\section{Acknowledgments}

Many of the interviews forming the data sources for this analysis were conducted during $>100$ sponsored commercial outdoor tours over the past 4 decades. I thank the tour operators, guides, and parent corporations for these opportunities. All interviews were conducted in accordance with the Griffith University Research Ethics Manual, the Australian National Statement on Ethical Conduct in Human Research, and local cultural norms. 
References

Aldiabat, K. M., \& Navenec, L. (2018). Data saturation: The mysterious step in grounded theory method. The Qualitative Report, 23, 245-261. Breitenstein, D., \& Ewert, A. (1990). Health benefits of outdoor recreation: Implications for health education. Health Education, 21, 16-21.

Buckley, R. C. (2016). Qualitative analysis of emotions: Fear and thrill. Frontiers in Psychology, 7, 1187.

Buckley, R. C., Brough, P., \& Westaway, D. (2018). Bringing outdoor therapies into mainstream mental health. Frontiers in Public Health, 6, 119. Buckley, R. C., \& Ollenburg, C. (2013). Tacit knowledge transfer: Cross cultural adventure. Annals of Tourism Research, 40, 419-422.

Chen, H. T., Yu, C. P., \& Lee, H. Y. (2018). The effects of forest bathing on stress recovery: Evidence from middle-aged females of Taiwan. Forests, 9, 403. Donaldson, G. W., \& Donaldson, L. E. (1958). Outdoor education: A definition. Journal of Health, Physical Education, Recreation, 29, 17-63. Frumkin, H., Bratman, G. N., Breslow, S. J., Cochran, B., Kahn, P. H., Lawler, J. J., et al. (2017). Nature contact and human health: A research agenda. Environmental Health Perspectives, 125, 075001-75011.

Glaser, B. G., \& Strauss, A. L. (2017). Discovery of grounded theory: Strategies for qualitative research. Oxford: Routledge. Konu, H. (2015). Developing a forest-based wellbeing tourism product together with customers - An ethnographic approach. Tourism Management, 49, 1-16. Matteucci, X., \& Gnoth, J. (2017). Elaborating on grounded theory in tourism research. Annals of Tourism Research, 65, 4959.

Nelson, J. (2017). Using conceptual depth criteria: Addressing the challenge of reaching saturation in qualitative research. Qualitative Research, 17, 554-570. Niedermeier, M., Hartl, A., \& Kopp, M. (2017). 
Prevalence of mental health problems and factors associated with psychological distress in mountain exercisers: A crosssectional study in Austria. Frontiers in Psychology, 8, 1237.

Oh, B. S., Lee, K. J., Zaslawski, C., Yeung, A., Rosenthal, D., Larkey, L., et al. (2017). Health and well-being benefits of spending time in forests: Systematic review.

Environmental Health and Preventive Medicine, 22, 71.

Ohe, Y., Ikei, H., Song, C., \& Miyazaki, Y. (2017). Evaluating the relaxation effects of emerging forest-therapy tourism: A multidisciplinary approach. Tourism Management, 62, 322-334.

Priest, S. (1986). Redefining outdoor education: A matter of many relationships. The Journal of Environmental Education, 17, 13-15. Richardson, M., \& McEwan, K. (2018). 30 Days Wild and the relationships between engagement with nature's beauty, nature connectedness and wellbeing. Frontiers in Psychology, 9, 1500.

Roberts, L., Jones, G., \& Brooks, R. (2018). Why do you ride? A characterisation of mountain bikers, their engagement methods, and perceived links to mental health and well-being. Frontiers in Psychology, 9, 1642.

Saunders, B., Sim, J., Kingstone, T., Baker, S., Waterfield, J., Bartlam, B., et al. (2018). Saturation in qualitative research: Exploring its conceptualization and operationalization. Quality \& Quantity, 52, 1893-1907.

Shanahan, D. F., Bush, R., Gaston, K. J., Lin, B. B., Dean, J., Barber, E., et al. (2016). Health benefits from nature experiences depend on dose. Scientific Reports, 6, 28551.

Smith, M. K., \& Diekmann, A. (2017). Tourism and wellbeing. Annals of Tourism Research, 66, 1-13.

Smith, M. K., \& Puczkó, L. (Eds.). (2016). The Routledge handbook of health tourism. London: Taylor \& Francis.

Stelzer, E. M., Book, S., Graessel, B. H., Kornhuber, J., \& Luttenberger, K. 
(2018). Bouldering psychotherapy reduces depressive symptoms even when general physical activity is controlled for: A randomized controlled trial. Heliyon, 4, e00580.

Stern, P. N., \& Porr, C. J. (2017). Essentials of accessible grounded theory. Oxford: Routledge.

Twohig-Bennett, C., \& Jones, A. (2018). The health benefits of the great outdoors: A systematic review and meta-analysis of greenspace exposure and health outcomes.

Environmental Research, 166, 628-637.

Ulrich, R. (1984). View through a window may influence recovery.

Science, 224, 420-421.

Van den Berg, A. E. (2017). From green space to green prescriptions:

Challenges and opportunities for research and practice. Frontiers in Psychology, 8, 268.

Wang, R. A. H., Nelson-Coffey, S. K., Layous, K., Bao, K. J., Davis, O. S., \& Haworth, C. M. (2017). Moderators of wellbeing interventions: Why do some people respond more positively than others? PLoS One, 12, e0187601. White, M. P., Elliott, L. R., Taylor, T., Wheeler, B. W., Spencer, A., Bone, A., et al. (2016). Recreational physical activity in natural environments and implications for health: A population based cross-sectional study in England. Preventive Medicine, 91, 383-388.

Wyles, K. J., White, M. P., Hattam, C., Pahl, S., King, H., \& Austen, M. (2017). Are some natural environments more psychologically beneficial than others? The importance of type and quality on connectedness to nature and psychological restoration. Environment and Behavior. https://doi.org/10.1177/ 0013916517738312. 
Table 1 Coding tree, concepts and constructs.

\begin{tabular}{|c|c|c|}
\hline Basic Concept & Mid-tier Construct & $\begin{array}{l}\text { High-tier } \\
\text { Construct }\end{array}$ \\
\hline $\begin{array}{l}\text { calm } \\
\text { peacefulness } \\
\text { happiness } \\
\text { joy }\end{array}$ & happy emotions & emotions \\
\hline $\begin{array}{l}\text { thrill } \\
\text { excitement } \\
\text { adventurousness }\end{array}$ & thrill emotions & \\
\hline $\begin{array}{l}\text { awe } \\
\text { wildness }\end{array}$ & awe emotions & \\
\hline $\begin{array}{l}\text { de-stress } \\
\text { de-tox } \\
\text { relax }\end{array}$ & escape stress & recovery \\
\hline $\begin{array}{l}\text { re-create } \\
\text { rebuild } \\
\text { restore }\end{array}$ & regenerate & \\
\hline $\begin{array}{l}\text { friendships } \\
\text { community }\end{array}$ & social & relationships \\
\hline $\begin{array}{l}\text { actions not talk } \\
\text { things not words }\end{array}$ & less talk, more action & unambiguous \\
\hline $\begin{array}{l}\text { clarity } \\
\text { insight } \\
\text { decisiveness } \\
\text { know what to do }\end{array}$ & clarity & worldview \\
\hline $\begin{array}{l}\text { pay attention } \\
\text { expansion } \\
\text { breadth } \\
\text { world is big }\end{array}$ & perception & \\
\hline $\begin{array}{l}\text { prioritisation } \\
\text { family cf work }\end{array}$ & priorities & philosophy \\
\hline $\begin{array}{l}\text { what's important } \\
\text { life is short } \\
\text { life purpose }\end{array}$ & meaning & \\
\hline life meaning & & \\
\hline
\end{tabular}


